\title{
Refractory Rhabdoid Tumor of the Kidney
}

National Cancer Institute

\section{Source}

National Cancer Institute. Refractory Rhabdoid Tumor of the Kidney. NCI Thesaurus.

Code C162731.

A rhabdoid tumor of the kidney that does not respond to treatment. 